\title{
Mid-regional pro-adrenomedullin and copeptin to predict short-term prognosis of COPD exacerbations: a multicenter prospective blinded study
}

\author{
This article was published in the following Dove Press journal: \\ International Journal of COPD \\ 31 March 2017 \\ Number of times this article has been viewed
}

\section{Martin Dres, ${ }^{1,2}$ Pierre Hausfater, ${ }^{3,4}$ Frantz Foissac, 5,6 Maguy Bernard, ${ }^{7}$ Luc-Marie Joly, ${ }^{8}$ Mustapha Sebbane, ${ }^{9}$ Anne-Laure Philippon, ${ }^{3,4}$ Cédric Gil-Jardiné, ${ }^{10}$ Jeannot Schmidt, " Maxime Maignan, ${ }^{12}$ Jean-Marc Treluyer, ${ }^{13}$ Nicolas Roche $^{14,15}$ \\ On behalf of the UTAPE Study Investigators and Scientific Committee}

'Pulmonary and Critical Care Department, Pitié-Salpêtrière Hospital, AP-HP, ${ }^{2}$ UMRSII 58: Clinical and Experimental Respiratory Neurophysiology, Paris 6 University, ${ }^{3}$ Emergency Department, Hôpital PitiéSalpêtrière, AP-HP, ${ }^{4}$ Sorbonne Universités UPMC Univ-Paris06, GRC-I 4 BIOSFAST, ${ }^{5}$ Clinical Research Department, Necker Cochin Hospital, AP-HP, ${ }^{6}$ EA 7323, Sorbonne Paris-Cité, ${ }^{7}$ Biochemistry Department, PitiéSalpêtrière Hospital, AP-HP, Paris, ${ }^{8}$ Emergency Department, Charles Nicolle Hospital, Rouen, ' Department of Emergency Medicine, Lapeyronie Hospital, Montpellier, ${ }^{10}$ Emergency Department, Pellegrin Hospital, Bordeaux, "Emergency Department, Gabriel Montpied Hospital, Clermont-Ferrand, ${ }^{12}$ Emergency Department, Grenoble University Hospital, Grenoble, ${ }^{13}$ Clinical Research Department, Paris Descartes University, Hôpital Cochin, AP-HP, ${ }^{14}$ Pulmonary Department, Cochin Hospital, AP-HP, ${ }^{15}$ Paris Descartes University, Paris, France

Correspondence: Nicolas Roche Department of Respiratory Diseases, Cochin Hospital, AP-HP and University Paris Descartes, Sorbonne Paris Cité, Paris 27 rue du Faubourg Saint-Jacques, 75014 Paris, France

Email nicolas.roche@aphp.fr
Background: Exacerbations of COPD (ECOPD) are a frequent cause of emergency room (ER) visits. Predictors of early outcome could help clinicians in orientation decisions. In the current study, we investigated whether mid-regional pro-adrenomedullin (MR-proADM) and copeptin, in addition to clinical evaluation, could predict short-term outcomes.

Patients and methods: This prospective blinded observational study was conducted in 20 French centers. Patients admitted to the ER for an ECOPD were considered for inclusion. A clinical risk score was calculated, and MR-proADM and copeptin levels were determined from a venous blood sample. The composite primary end point comprised 30-day death or transfer to the intensive care unit or a new ER visit.

Results: A total of 379 patients were enrolled in the study, of whom 277 were eventually investigated for the primary end point that occurred in $66(24 \%)$ patients. In those patients, the median (interquartile range [IQR]) MR-proADM level was $1.02 \mathrm{nmol} / \mathrm{L}(0.77-1.48)$ versus $0.83 \mathrm{nmol} / \mathrm{L}(0.63-1.07)$ in patients who did not meet the primary end point $(P=0.0009)$. In contrast, copeptin levels were similar in patients who met or did not meet the primary end point $(P=0.23)$. MR-proADM levels increased with increasing clinical risk score category: $0.74 \mathrm{nmol} / \mathrm{L}(0.57-0.89), 0.83 \mathrm{nmol} / \mathrm{L}(0.62-1.12)$ and $0.95 \mathrm{nmol} / \mathrm{L}(0.75-1.29)$ for the low-, intermediate- and high-risk categories, respectively $(P<0.001)$. MR-proADM was independently associated with the primary end point (odds ratio, 1.65; 95\% confidence interval [CI], 1.10-2.48; $P=0.015)$. MR-proADM predicted the occurrence of primary end point with a sensitivity of $46 \%(95 \%$ CI, 33\%-58\%) and a specificity of 79\% (95\% CI, 74-84).

Conclusion: MR-proADM but not copeptin was significantly associated with outcomes at 30 days, even after adjustment for clinical risk category. Overall, MR-proADM, alone or combined with the clinical risk score, was a moderate strong predictor of short-term outcomes.

Keywords: COPD, mid-regional pro-adrenomedullin, copeptin, biomarker, emergency department

\section{Introduction}

COPD has a major impact on individuals and on the society. ${ }^{1}$ Exacerbations represent a major component of COPD-related burden, during both the acute phase and chronic management. They are important causes of unscheduled physician visits and hospital admissions. ${ }^{2-4}$ There is a wide range of disease severity among hospitalized patients with exacerbations of COPD (ECOPD), ranging from brief emergency room (ER) admission to prolonged hospital stay and death. Although most exacerbations are managed 
at home, patients visiting ERs are often hospitalized, which is in part due to difficulties in predicting outcome based on initial observations. Several studies have aimed at developing accurate assessment strategies to help caregivers identifying patients at risk of worsening. ${ }^{5-7}$ A clinical risk score based on underlying dyspnea severity, age and clinical signs of severity was proposed in 2008 and subsequently modified in 2014 with the inclusion of cardiovascular comorbidities. ${ }^{8,9}$ This score categorizes patients into 3 risk categories (low, intermediate and high risk) with acceptable performance to predict in-hospital mortality for patients visiting ERs or hospitalized for ECOPD. ${ }^{8}$ Recently, plasma biomarkers are of increasing interest as a means to characterize disease severity and prognosis in this context. ${ }^{10-12}$ Mid-regional pro-adrenomedullin (MR-proADM) and copeptin have been investigated as markers of long-term outcomes of COPD patients, ${ }^{11,13}$ but not specifically for the prediction of short-term outcomes of COPD exacerbations. Therefore, the current study aimed at determining whether the prognostic value of MR-proADM and/or copeptin added to the abovementioned clinical risk score could accurately predict short-term outcomes of COPD exacerbations.

\section{Patients and methods}

\section{Study design}

This prospective blinded observational study was conducted in 20 centers across France. Centers were asked to prospectively include patients visiting their ER between November 2011 and November 2014 with a certain or probable diagnosis of COPD exacerbation. Patients were followed up until 30 days after inclusion. The protocol was approved by the Comité de Protection des Personnes Ile de France 1 (2012-A01237-36). Written informed consent was obtained from all patients. The study was registered on ClinicalTrials.gov: NCT01857947.

\section{Inclusion and non-inclusion criteria}

Patients were included if they presented with a probable or certain ECOPD, as defined by the appearance or worsening of dyspnea in a patient with known COPD or risk factors for COPD (age $>40$ years and current or past cumulative tobacco consumption of $>10$ pack-years) and no evidence for an alternative diagnosis: ${ }^{14}$ specifically, patients were not included when the investigator judged that the predominant diagnosis was or was likely to be pneumonia, pulmonary embolism, congestive heart failure and pneumothorax or when the predominant underlying respiratory disease was asthma, bronchiectasis, congestive heart failure, thromboembolic disease or restrictive respiratory insufficiency. Patients requiring immediate intensive care unit monitoring and/or noninvasive or invasive ventilation were not included.

\section{Data collection}

The following data were collected: age, sex, comorbid conditions, smoking history, known diagnosis of COPD, chronic bronchitis or emphysema, age at first respiratory symptoms, usual severity of dyspnea at steady state using the modified Medical Research Council scale, self-reported number of emergency visits and hospitalizations during the past 6 months and maintenance treatments. The history of the current exacerbation, dyspnea grade at entry and clinical signs of severity, as well as results of routine venous and arterial blood sampling and chest X-ray, were recorded. Diagnostic procedures and treatments in the hospital were collected. Upon discharge, the local coordinating respiratory physician was requested to provide his/her final conclusions regarding the diagnosis (confirmed ECOPD or alternative diagnosis) and the certain or probable etiology of the exacerbation.

\section{Blood sample for MR-proADM and copeptin plasma level determination}

All blood samples were collected on patient's admission and were stored for subsequent blinded determination (Supplementary materials).

\section{Study end points}

The primary end point was a composite outcome defined by death, transfer to the intensive care unit or new exacerbation requiring hospitalization or ER visit within 30 days after enrollment. The main secondary end point was the same composite variable within 7 days of enrollment.

\section{Statistical analysis}

Sample size was calculated assuming an estimated prevalence of the primary end point of $30 \%$ and a mean (standard deviation) of $0.8(0.5) \mathrm{nmol} / \mathrm{L}$ for MR-proADM levels. ${ }^{11}$ According to statistical simulations on the basis of a 2 -sided comparison at 5\% significance level with $80 \%$ power, 250 patients would allow to estimate an odds ratio (OR) of 2.1 between risk categories.

The analysis included patients in whom MR-proADM and copeptin plasma level, variables involved in the primary composite end point and variables of the 2008 clinical score $^{8}$ were available. Continuous variables are presented as medians (interquartile range $[\mathrm{IQR}]$ ) and discrete variables as percentage. Qualitative variables were compared using the chi-square test or the Fisher's exact test (as appropriate). 
Quantitative variables were analyzed by Student's $t$-test or by the nonparametric Wilcoxon-Mann-Whitney test (if normality could not be established). Comparison of 3 or more means was performed by ANOVA or Kruskal-Wallis test, as appropriate. The Spearman correlation was used to evaluate the relationship between MR-proADM and clinical risk score category and clinical/biological variables.

All hypothesis tests were 2 -sided at the $5 \%$ level of significance. Statistical analyses were performed by using ad hoc routines implemented in $\mathrm{R}$ 3.2.0 software.

A 4-step analytical plan was applied to explore the primary objective of the study. The first step was the comparison of MR-proADM levels between patients who met and those who did not meet the primary end point. Second, receiver operating characteristic (ROC) curves were built using the ROCR package ${ }^{15}$ to assess the global performance of MR-proADM to predict the occurrence of the primary end point and to define the optimal cutoff. A bootstrap method was used to calculate the $95 \%$ confidence interval (CI) of areas under the ROC curves, sensitivities and specificities. Third, the 2008 clinical risk score ${ }^{8}$ was calculated and the patients were allocated to the risk categories. Finally, a multivariate logistic regression analysis assessed the predictive performance of the MR-proADM plasma levels after adjustment on the 2008 clinical score. The same strategy was followed for copeptin.

\section{Results \\ Population}

From the 379 patients eligible for inclusion during the study period, 277 were finally included in the analyses (Figure 1). Among them, 247 (89\%) were known to have a COPD, 142 (51\%) had a 4 or 5 baseline dyspnea grade and $137(50 \%)$ had at least 1 ECOPD in the previous year (Table 1).

\section{Occurrence of the primary and secondary end points}

The primary end point occurred in 66 (24\%) patients: 14 died, 25 were transferred to the intensive care unit and 35 had a

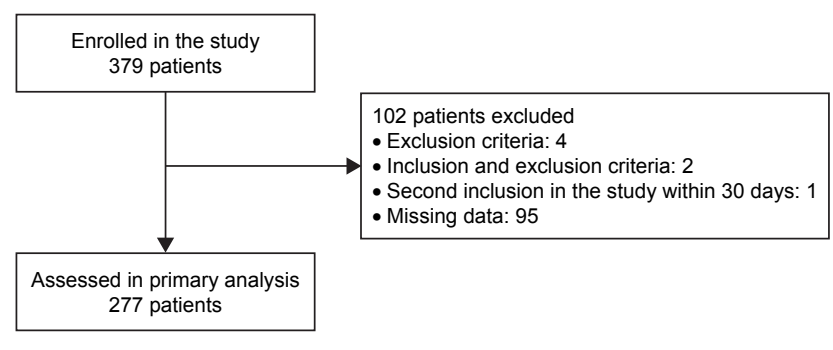

Figure I Flowchart of the study.
Table I Characteristics of the population

\begin{tabular}{|c|c|}
\hline Characteristics & $\mathrm{n}=\mathbf{2 7 7}$ \\
\hline \multicolumn{2}{|l|}{ Demographic description } \\
\hline Age, years & $69(62-78)$ \\
\hline Male, n (\%) & $179(65)$ \\
\hline Body mass index, $\mathrm{kg} \cdot \mathrm{m}^{-2}$ & $25(2|-4|)$ \\
\hline Current smokers, n (\%) & II 4 (42) \\
\hline Cumulative smoking consumption, pack-years & $47(3 \mid-60)$ \\
\hline Ex-smokers, n (\%) & $135(5 \mid)$ \\
\hline Known COPD, n (\%) & $247(89)$ \\
\hline Institutionalization, n (\%) & $20(7)$ \\
\hline \multicolumn{2}{|l|}{ Baseline dyspnea grade, $\mathrm{n}(\%)$} \\
\hline 1 & $12(4)$ \\
\hline 2 & $49(18)$ \\
\hline 3 & $74(27)$ \\
\hline 4 & $70(25)$ \\
\hline 5 & $72(26)$ \\
\hline \multicolumn{2}{|c|}{ Hospitalization for COPD exacerbation in the last year, n (\%) } \\
\hline 0 & $138(50)$ \\
\hline 1 & $51(19)$ \\
\hline 2 & $47(17)$ \\
\hline$>3$ & $39(14)$ \\
\hline \multicolumn{2}{|l|}{ Usual maintenance treatment, $\mathrm{n}(\%)$} \\
\hline Short-acting $\beta 2$-agonists & $145(52)$ \\
\hline Anticholinergic agents & II $5(42)$ \\
\hline Inhaled corticosteroids & $58(2 I)$ \\
\hline Oral corticosteroids & $43(15)$ \\
\hline Long-term oxygen therapy & $67(24)$ \\
\hline Noninvasive ventilation & $24(9)$ \\
\hline \multicolumn{2}{|l|}{ Comorbidities, n (\%) } \\
\hline Ischemic heart disease & $47(2 \mathrm{I})$ \\
\hline Chronic left ventricular failure & $23(10)$ \\
\hline Diabetes mellitus & $50(22)$ \\
\hline Chronic renal failure & $17(8)$ \\
\hline
\end{tabular}

Note: Data are expressed as median (IQR) or $\mathrm{n}(\%)$.

Abbreviation: IQR, interquartile range.

new COPD exacerbation in the 30 following days ( 8 patients encountered 2 events). There was no difference between patients with and without occurrence of the primary end point in terms of signs of severity (as used in the 2008 risk score) and treatments administered in the ER (Table 2). However, respiratory rate and $\mathrm{PaCO}_{2}$ was higher in patients in whom the primary end point occurred. The secondary end point occurred in $34(12.3 \%)$ patients (Table S1).

\section{MR-proADM and clinical risk score}

In the whole population, MR-proADM concentration was $0.87 \mathrm{nmol} / \mathrm{L}(0.67-1.15)$. In patients who met and did not meet the primary end point, it was $1.02 \mathrm{nmol} / \mathrm{L}(0.77-1.48)$ and $0.83 \mathrm{nmol} / \mathrm{L}(0.63-1.07)$, respectively $(P=0.0009$; Figure 2, Table 3). In patients who met and in those who did not meet the secondary end point, MR-proADM was $1.18 \mathrm{nmol} / \mathrm{L}(0.81-1.86)$ and $0.84 \mathrm{nmol} / \mathrm{L}(0.67-1.11)$, respectively $(P=0.003$; Table $\mathrm{S} 1)$. 
Table 2 Initial presentation and management according to the occurrence of the primary outcome

\begin{tabular}{|c|c|c|c|c|}
\hline \multirow[t]{2}{*}{ Patient's characteristics } & \multirow[t]{2}{*}{ All patients $(n=277)$} & \multicolumn{2}{|l|}{ Primary outcome } & \multirow[t]{2}{*}{$P$-value } \\
\hline & & Yes $(n=66)$ & No $(n=2 I I)$ & \\
\hline \multicolumn{5}{|l|}{ Increased/recent symptoms, n (\%) } \\
\hline Cough & $205(74)$ & $46(70)$ & $159(75)$ & 0.45 \\
\hline Expectoration abundance & $145(52)$ & $37(56)$ & $108(5 \mathrm{I})$ & 0.61 \\
\hline Sputum purulence & $95(34)$ & $21(32)$ & $74(35)$ & 0.76 \\
\hline \multicolumn{5}{|l|}{ Signs of severity, $\mathrm{n}(\%)$} \\
\hline 0 & $81(29)$ & $16(24)$ & $65(31)$ & 0.32 \\
\hline $1-2$ & $152(55)$ & $36(54)$ & $116(55)$ & \\
\hline$>3$ & $44(16)$ & $14(2 \mid)$ & $30(14)$ & \\
\hline Cyanosis & $48(17)$ & $13(20)$ & $35(17)$ & 0.69 \\
\hline Neurological impairment & $6(2)$ & $3(4)$ & $3(1)$ & 0.15 \\
\hline Lower limb edema & $53(19)$ & $15(23)$ & $38(18)$ & 0.50 \\
\hline Asterixis & $14(5)$ & $5(8)$ & $9(4)$ & 0.33 \\
\hline Use of accessory inspiratory muscles & $158(57)$ & $4 \mid(62)$ & $117(56)$ & 0.42 \\
\hline Expiratory use of abdominal muscles & $109(39)$ & $30(46)$ & $79(37)$ & 0.31 \\
\hline \multicolumn{5}{|l|}{ Physiological variables } \\
\hline Systolic arterial pressure, $\mathrm{mmHg}$ & $142(123-160)$ & $147(122-170)$ & $140(\mid 23-157)$ & 0.19 \\
\hline Diastolic arterial pressure, $\mathrm{mmHg}$ & $79(68-90)$ & $83(7 \mid-94)$ & 79 (67-89) & 0.017 \\
\hline Respiratory rate, $\mathrm{min}^{-1}$ & $26(22-30)$ & $29(24-32)$ & $26(20-30)$ & 0.032 \\
\hline Heart rate, $\min ^{-1}$ & $95(84-108)$ & $94(80-108)$ & $96(84-108)$ & 0.70 \\
\hline $\mathrm{SpO}_{2}, \%$ & $93(90-96)$ & $94(90-96)$ & $93(90-96)$ & 0.59 \\
\hline \multicolumn{5}{|l|}{ Clinical risk score, n (\%) } \\
\hline Low risk & $44(16)$ & $7(I I)$ & $37(18)$ & 0.15 \\
\hline Intermediate risk & $113(4 I)$ & $24(36)$ & $89(42)$ & \\
\hline High risk & $120(43)$ & $35(53)$ & $85(40)$ & \\
\hline \multicolumn{5}{|l|}{ Blood gases } \\
\hline $\mathrm{pH}$ & $7.39(7.34-7.43)$ & $7.36(7.30-7.41)$ & $7.40(7.35-7.44)$ & 0.001 \\
\hline $\mathrm{PaCO}_{2}, \mathrm{mmHg}$ & $46(39-56)$ & $52(42-65)$ & $46(39-55)$ & 0.005 \\
\hline $\mathrm{PaO}_{2}, \mathrm{mmHg}$ & $68(56-86)$ & $68(59.5-90)$ & $67(55-84)$ & 0.28 \\
\hline Lactate, $\mathrm{mmol} / \mathrm{L}$ & $1.2(1.0-1.8)$ & I.I (0.9-I.5) & $1.3(1.0-2.0)$ & 0.11 \\
\hline \multicolumn{5}{|l|}{ Treatments administered in ER, $\mathrm{n}(\%)$} \\
\hline Antibiotics & II $5(4 I)$ & $32(48)$ & $83(39)$ & 0.08 \\
\hline Short-acting $\beta 2$-agonists & $245(88)$ & $59(89)$ & $186(88)$ & 0.96 \\
\hline Anticholinergic agents & $228(82)$ & $54(82)$ & $174(82)$ & 0.99 \\
\hline Oral corticosteroids & $27(9)$ & $7(\mathrm{II})$ & $20(9)$ & 0.98 \\
\hline Oxygen therapy & $125(55)$ & $33(50)$ & $92(44)$ & 0.44 \\
\hline Noninvasive ventilation & $45(16)$ & $13(20)$ & $32(15)$ & 0.50 \\
\hline \multicolumn{5}{|l|}{ Biomarkers } \\
\hline MR-proADM, nmol/L & $0.87(0.67-1.15)$ & $1.02(0.77-1.48)$ & $0.83(0.63-1.07)$ & 0.0009 \\
\hline Copeptin, pmol/L & | $3.06(5.95-33.43)$ & $|4.7|(6.25-40.13)$ & $|2.7|(5.89-3 \mid .08)$ & 0.23 \\
\hline
\end{tabular}

Notes: Primary outcome was a composite outcome defined by death, transfer to intensive care unit or new exacerbation requiring hospitalization or ER visit within 30 days after enrollment. Data are expressed as median (IQR) or $n$ (\%).

Abbreviations: ER, emergency room; IQR, interquartile range; MR proADM, mid-regional pro-adrenomedullin.

Using the clinical risk score, $44(16 \%)$ patients were classified as low risk, 113 (41\%) patients as intermediate risk and $120(43 \%)$ as high risk. MR-proADM levels increased with increasing risk category: $0.74 \mathrm{nmol} / \mathrm{L}(0.57-0.89)$, $0.83 \mathrm{nmol} / \mathrm{L}(0.62-1.12)$ and $0.95 \mathrm{nmol} / \mathrm{L}(0.75-1.29)$ for the low-, intermediate- and high-risk categories, respectively $(P<0.001)$. The correlation between MR-proADM and the clinical risk score category was significant (Spearman $R$ value $=0.27 ; P<0.0001$ ). The correlations between MR-proADM and the main clinical and arterial blood gases variables are given in Table $\mathrm{S} 2$.

\section{MR-proADM for the prediction of primary and secondary end points: multivariate models adjusting for clinical risk score}

MR-proADM was independently associated with the primary end point (OR, 1.65; 95\% CI, 1.10-2.48; $P=0.015)$ and with the secondary end point (OR, 1.99; 95\% CI, 1.27-3.11; $P=0.002$; Table 4).

With a cutoff of $1.13 \mathrm{nmol} / \mathrm{L}$, MR-proADM predicted the occurrence of the primary end point with a sensitivity 


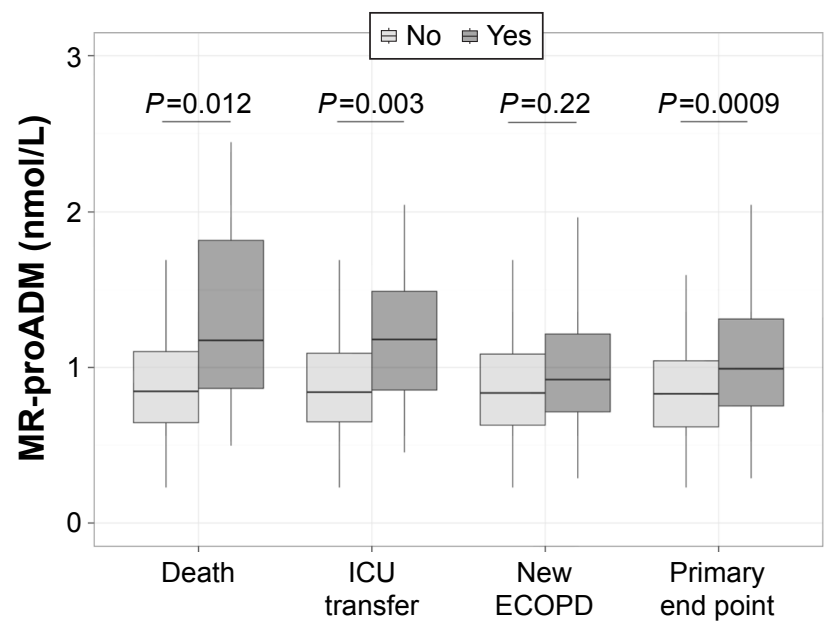

Figure 2 MR-proADM plasma level according to the primary end point and to each outcome of interest at day 30: mortality, ICU transfer and new exacerbation (ECOPD) requiring hospitalization.

Abbreviations: ICU, intensive care unit; MR-proADM, mid-regional proadrenomedullin.

of $46 \%(95 \% \mathrm{CI}, 33 \%-58 \%)$ and a specificity of $79 \%$ (95\% CI, 74-84) (area under the ROC curve, $0.64[95 \%$ CI, 0.55-0.71]; Figure 3).

Regarding the secondary end point, the area under the ROC curve was of 0.65 (95\% CI, 0.53-0.75) and the MRproADM cutoff value of $1.13 \mathrm{nmol} / \mathrm{L}$ provided a sensitivity of $56 \%(95 \%$ CI, 38\%-74\%) and a specificity of 77\% (95\% CI, 72-83; Figure S1A). Adjusting for the clinical risk score did not improve the diagnostic performance (area under the ROC curve of 0.68 [95\% CI, 0.58-0.77]). For both primary and secondary end points, similar features were obtained when MR-proADM and clinical risk score were associated (Figures 3 and S1A).
Copeptin for the prediction of primary and secondary end point: multivariate models adjusting for clinical risk score

In the whole population, copeptin concentration was $13.06 \mathrm{pmol} / \mathrm{L}$ (5.95-33.43). Copeptin levels were similar in patients who met or did not meet the primary end point $(P=0.23$; Table 2$)$ but significantly higher in patients who met the secondary end point ( $P=0.004$; Table S1). Accordingly, copeptin was not associated with the primary end point (OR, 1.04; 95\% CI, 0.99-1.09; $P=0.09$ ) but was independently associated with the secondary end point (OR, 1.08; 95\% CI, 1.02-1.14; $P=0.006$; Table 5). With a cutoff of $37.5 \mathrm{pmol} / \mathrm{L}$, copeptin predicted the occurrence of the secondary end point with a sensitivity of $47 \%(95 \% \mathrm{CI}$, $29 \%-65 \%)$ and a specificity of $82 \%$ (95\% CI, 77-87; area under the ROC curve, 0.65; 95\% CI, 0.54-0.76). Similar predictive properties were observed when copeptin and clinical risk score were associated (Figure S1B).

\section{Discussion}

This prospective multicenter study is the first to concurrently assess the properties of MR-proADM and copeptin to predict short-term outcomes of patients visiting the ERs for an ECOPD, accounting for the clinical risk category. High levels of MR-proADM but not copeptin were significantly associated with worse outcomes at 30 days, even after adjustment for clinical risk category. The analysis of ROC curves found that MR-proADM, alone or in combination with the clinical risk category, was a moderate strong predictor of short-term outcomes. Both MR-proADM and copeptin were associated with 7-day outcomes in both univariate and multivariate

Table 3 Occurrence of the primary and secondary outcomes according to the clinical risk score and MR-proADM

\begin{tabular}{|c|c|c|c|c|c|c|c|}
\hline \multirow{2}{*}{$\begin{array}{l}\text { Biomarkers and } \\
\text { outcomes }\end{array}$} & \multicolumn{3}{|l|}{ Clinical risk score } & \multirow[t]{2}{*}{$P$-value } & \multicolumn{2}{|l|}{ MR-proADM } & \multirow[t]{2}{*}{$P$-value } \\
\hline & $\begin{array}{l}\text { Low risk } \\
(n=44)\end{array}$ & $\begin{array}{l}\text { Intermediate } \\
\text { risk }(n=|| 3)\end{array}$ & $\begin{array}{l}\text { High risk } \\
(n=\mid 20)\end{array}$ & & $\begin{array}{l}<\mathrm{I} .13 \mathrm{nmol} / \mathrm{L}^{*} \\
(\mathrm{n}=203)\end{array}$ & $\begin{array}{l}\geq 1.13 \mathrm{nmol} / \mathrm{L} \\
(\mathrm{n}=74)\end{array}$ & \\
\hline MR-proADM, nmol/L & $0.74(0.57-0.89)$ & $0.83(0.62-1.12)$ & $0.95(0.75-1.29)$ & $<0.0001$ & $0.75(0.58-0.90)$ & $1.49(1.26-1.99)$ & - \\
\hline Copeptin, pmol/L & $9.66(3.53-27.16)$ & $12.43(6.35-33.62)$ & $17.66(6.38-33.62)$ & 0.013 & - & - & - \\
\hline \multicolumn{8}{|l|}{ At day 30} \\
\hline Death, n (\%) & $2(4.5)$ & $3(2.7)$ & $9(7.5)$ & 0.28 & $8(3.9)$ & $6(8.1)$ & 0.013 \\
\hline ICU transfer, n (\%) & $2(4.7)$ & $9(8.0)$ & $14(11.9)$ & 0.37 & II (5.5) & $14(19.2)$ & 0.001 \\
\hline New ECOPD, n (\%) & $4(9.3)$ & $14(12.5)$ & $17(5.8)$ & 0.62 & $22(11.1)$ & $13(18.6)$ & 0.17 \\
\hline Primary end point, $n(\%)$ & $7(\mid 5.9)$ & $24(21.2)$ & $35(29.2)$ & 0.15 & $36(17.7)$ & $30(40.5)$ & 0.0002 \\
\hline \multicolumn{8}{|l|}{ At day 7} \\
\hline Death, n (\%) & $0(-)$ & $0(-)$ & $6(5.0)$ & 0.028 & $2(1.0)$ & $4(5.4)$ & 0.046 \\
\hline ICU transfer, n (\%) & $\mathrm{I}(2.3)$ & $8(7.1)$ & $12(10.0)$ & 0.27 & $9(4.5)$ & $12(16.2)$ & 0.002 \\
\hline New ECOPD, n (\%) & $\mathrm{I}(2.3)$ & $6(5.3)$ & $3(2.5)$ & 0.56 & $6(3.0)$ & $4(5.4)$ & 0.47 \\
\hline Secondary end point, n (\%) & $2(4.7)$ & $13(11.5)$ & $19(15.8)$ & 0.15 & $15(7.4)$ & $19(25.7)$ & 0.0001 \\
\hline
\end{tabular}

Note: *The cutoff of $1.13 \mathrm{nmol} / \mathrm{L}$ was the threshold of MR-proADM providing the best combination of sensitivity and specificity for the occurrence of the primary end point.

Abbreviations: ECOPD, exacerbation of COPD; ICU, intensive care unit; MR-proADM, mid-regional pro-adrenomedullin. 
Table 4 Multivariate logistic regression to predict the occurrence of the primary and secondary end points

\begin{tabular}{|c|c|c|c|c|c|c|}
\hline \multirow{2}{*}{$\begin{array}{l}\text { Biomarkers } \\
\text { and } \\
\text { outcomes }\end{array}$} & \multicolumn{2}{|c|}{$\begin{array}{l}\text { Primary } \\
\text { outcome }\end{array}$} & \multirow[t]{2}{*}{$P$-value } & \multicolumn{2}{|c|}{$\begin{array}{l}\text { Secondary } \\
\text { outcome }\end{array}$} & \multirow[t]{2}{*}{$P$-value } \\
\hline & OR & $95 \% \mathrm{Cl}$ & & OR & $95 \% \mathrm{Cl}$ & \\
\hline $\begin{array}{l}\text { MR-proADM } \\
\text { (nmol/L) }\end{array}$ & 1.65 & I.10-2.48 & 0.015 & 1.99 & $1.27-3.11$ & 0.002 \\
\hline \multicolumn{7}{|c|}{ Clinical risk score } \\
\hline Low & I & - & - & 1 & - & - \\
\hline Medium & 1.24 & $0.48-3.18$ & 0.64 & 2.17 & $0.46-10.10$ & 0.33 \\
\hline High & 1.72 & $0.68-4.34$ & 0.24 & 2.67 & $0.57-12.39$ & 0.21 \\
\hline
\end{tabular}

Note: Models including MR-proADM and clinical risk score category.

Abbreviations: $\mathrm{Cl}$, confidence interval; MR-proADM, mid-regional proadrenomedullin; OR, odds ratio.

analyses adjusting for clinical risk category, again with moderate strong discriminative properties.

\section{Prognostic value of MR-proADM}

Several investigations highlighted the interest of plasma biomarkers and their combination with clinical features to improve risk stratification in various acute respiratory conditions such as COPD exacerbations or community-acquired pneumonia. ${ }^{16-20}$ MR-proADM is a promising biomarker ${ }^{21-23}$ that has been actively investigated as a tool to improve risk stratification in COPD patients. ${ }^{11,18,24}$ During COPD exacerbations, MR-proADM levels increase, ${ }^{11,24}$ suggesting that

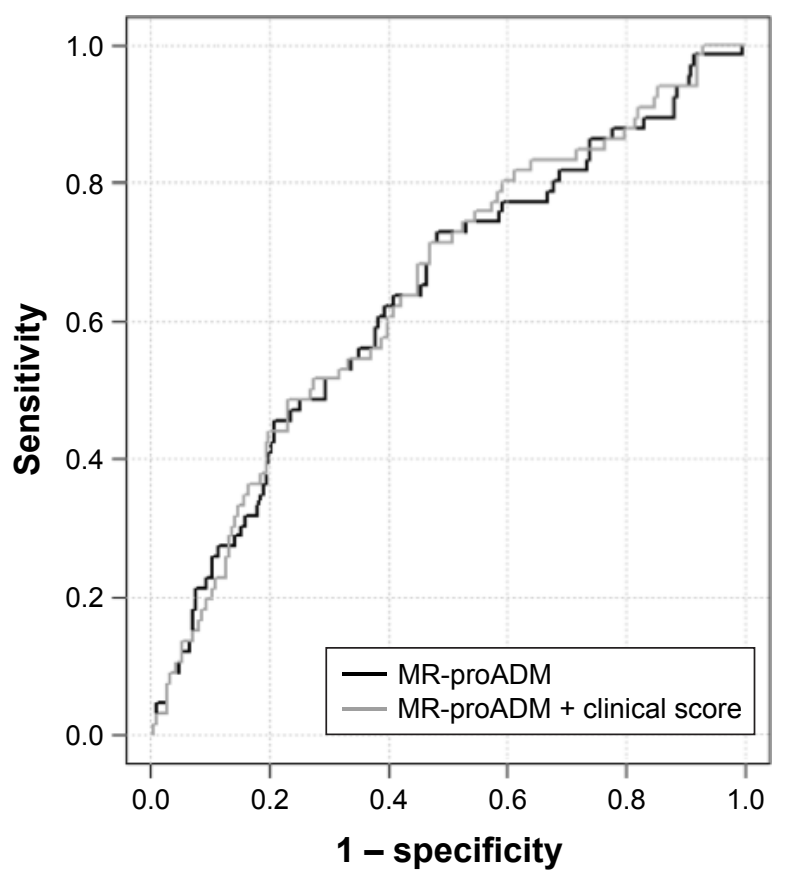

Figure 3 ROC curves showing the performance of the plasma level of MR-proADM or MR-proADM associated with clinical risk score to predict the primary end point. Abbreviations: MR-proADM, mid-regional pro-adrenomedullin; ROC, receiver operating characteristic.
Table 5 Multivariate logistic regression to predict the occurrence of the primary and secondary end points

\begin{tabular}{|c|c|c|c|c|c|c|}
\hline \multirow{2}{*}{$\begin{array}{l}\text { Biomarkers } \\
\text { and } \\
\text { outcomes }\end{array}$} & \multicolumn{2}{|c|}{$\begin{array}{l}\text { Primary } \\
\text { outcome }\end{array}$} & \multirow[t]{2}{*}{$P$-value } & \multicolumn{2}{|c|}{$\begin{array}{l}\text { Secondary } \\
\text { outcome }\end{array}$} & \multirow[t]{2}{*}{$P$-value } \\
\hline & $\overline{\text { OR }}$ & $95 \% \mathrm{Cl}$ & & OR & $95 \% \mathrm{Cl}$ & \\
\hline $\begin{array}{l}\text { Copeptin, } \\
\mathrm{pmol} / \mathrm{L}\end{array}$ & 1.04 & $0.99-1.09$ & 0.09 & 1.08 & $1.02-1.14$ & 0.006 \\
\hline \multicolumn{7}{|c|}{ Clinical risk score } \\
\hline Low & I & - & - & I & - & - \\
\hline Medium & $\mathrm{I} .4$ & $0.55-3.53$ & 0.48 & 2.55 & $0.55-11.85$ & 0.23 \\
\hline High & 1.95 & $0.78-4.83$ & 0.15 & 3.10 & $0.68-14.20$ & 0.14 \\
\hline
\end{tabular}

Note: Models including copeptin and clinical risk score category.

Abbreviations: $\mathrm{Cl}$, confidence interval; $\mathrm{OR}$, odds ratio.

it could be of special interest in that specific context. In the current study, we confirmed previous reports, ${ }^{11,24}$ showing that MR-proADM levels on admission are higher in patients with subsequently worse outcomes. Even after adjustment for the clinical risk score category, MR-proADM remained independently associated with outcomes at 7 and 30 days. However, MR-proADM levels were only a moderate strong predictor of short-term outcomes. In contrast, MR-proADM has previously been established as a powerful predictor of long-term risk of death in COPD patients. ${ }^{18,24,25}$ One hypothesis to explain this discrepancy is that the value of MR-proADM as a predictor of short-term outcomes during exacerbations could be influenced by the etiology/phenotype of the event, ${ }^{26}$ the severity/phenotype of the underlying disease and/or the presence of comorbidities, all of which being known determinants of outcomes. ${ }^{14,27}$ Our study was not designed to test this possibility: a systematic process was not used to investigate the underlying COPD phenotype, exacerbations' etiologies and underlying mechanisms and the sample size would not be sufficient to perform reliable subgroup analyses.

Our findings are partly in line with the study by Stolz et $\mathrm{al},{ }^{11}$ in which the relationship between MR-proADM levels and long-term outcomes (survival, hospital admission) appeared stronger than with short-term (in-hospital) mortality in patients with COPD exacerbations. The levels of MR-proADM observed at exacerbation in that study were comparable to what we found. Interestingly, the frequency of comorbid heart disease (45\%) was markedly higher than in our study (10\%), which may help explaining the difference in prognostic value of the biomarker. Along the same line, in our study but not in that of Stolz et al, ${ }^{11}$ investigators were informed to exclude patients with suspected heart failure or pneumonia. This may be of importance to explain the lower short-term prognostic value in our study compared to that 
of Stolz et al, ${ }^{11}$ since MR-proADM has been associated with cardiovascular stress and infection. ${ }^{28}$

While MR-proADM may be a useful marker of long-term prognosis in COPD, ${ }^{11,25}$ it appears unlikely to be a powerful predictor of short-term outcomes in acute COPD-related events, at least in patients with relatively "pure" exacerbations, ie, excluding those in whom heart failure or pneumonia could be involved. In this regard, our findings are somehow similar to a recent study showing that in patients with acute dyspnea admitted in the ERs, measurements of pro-hormone type biomarkers had only a low added value to clinical signs for the prediction of poor outcome. ${ }^{29}$

\section{Prognostic value of copeptin}

The performance of copeptin in predicting short- and longterm mortality in COPD patients with exacerbation was reported previously. ${ }^{13,30,31}$ In our study, while copeptin levels increased with the clinical risk score, it failed to predict the composite primary outcome, in contrast to what we found with MR-proADM. However, copeptin levels were significantly higher in our patients who met the 7-day composite end point. Interestingly, we found that the best cutoff in copeptin level predicting this secondary end point was very close to what has been already reported. ${ }^{13}$ These findings suggest that copeptin would rather be considered as a marker of early outcome. Nevertheless, as MR-proADM, its performance to predict 7-day outcomes was rather low.

\section{Strengths and limitations of the study}

The main strength of the current study is the prospective multicenter design, enhancing the generalizability and reliability of results. Another strength is the use of a composite end point, better reflecting the potential complications that may affect a COPD patient after ER discharge.

Some limitations have to be acknowledged. First, patients were only followed up until day 30 , since our main interest was to develop a combined clinical and biological tool easily available in the ER to help clinicians in the decisionmaking process in terms of orientation and triage. Second, the prevalence of the primary outcome was slightly lower than expected, which decreases the power of the analyses. However, although this might make it more difficult to achieve statistical significance, it would not change the magnitude of associations. Third, the severity of COPD in our population was not easily comparable to other studies since lung function measurements were inconsistently available. However, half of the patients had a baseline dyspnea score of 4 or 5 , reflecting severe disease.

\section{Conclusion}

In COPD patients admitted to the ER for exacerbations, MR-proADM was significantly associated with the risk of poor outcome at 7 and 30 days, even after adjustment for the clinical risk category. However, the predictive value was relatively modest, as assessed by the area under the ROC curve. Copeptin was only associated with 7-day outcomes. Additional studies are required to further explore how these biomarkers could be integrated in predictive rules aiming at identifying patients at risk of poor early outcomes.

\section{Acknowledgments}

The study was an investigator-initiated study primarily funded by Thermo Scientific Biomarkers (formerly BRAHMS AG), Hennigsdorf, Germany, which provided all reagents gratis and, through an unrestricted research grant, funded all shipment costs of blood samples to the central biomarker testing facility at University Hospital Pitié-Salpêtrière. Drs Martin Dres, Nicolas Roche, Pierre Hausfater, Thomas Similowski, Jean-Marc Treluyer and Patrick Plasisance are the members of the UTAPE Scientific Committee. The list of the UTilité de la pro-Adrénomédulline comme facteur Prédictif d'évolution des Exacerbations de BPCO (UTAPE) study investigators is as follows: Patrick Plaisance (Lariboisiere Hospital, Paris), Arnaud Martinage (CHU Nantes), Nicolas Fraimout (CHU Nice), Pierre-Géraud Claret (Hôpital Carrémeau, Nîmes), Karim Tazarourte (CH Marc Jacquet, Melun), Eric Roupie (CHU Caen), Patrick Ray (Tenon Hospital, Paris), Paul Gayol (Hôpitaux Universitaires de Strasbourg - Hôpital Civil), Philippe Sattonnet (Hôpital Bel-Air CHR Metz-Thionville), Fatima Rayeh (CHU Poitiers), Dominique Savary (CHR Annecy), Bertrand Renaud (CHU Cochin, Paris), Mehdi Khellaf (CHU Henri Mondor, Créteil) and Sébastien Beaune (CHU Ambroise Paré, Boulogne Billancourt).

\section{Author contributions}

Drs MD, PH and NR contributed to conception and design of the study, collection, analysis and interpretation of data, generation of figures and drafting and revising the article. Drs MB, L-MJ, MS, A-LP, CG-J, JS and MM contributed to data collection and article revision. FF performed the statistical analysis. All the authors approved the final version of this article, including the authorship list. All authors contributed toward data analysis, drafting and revising the paper and agree to be accountable for all aspects of the work. 


\section{Disclosure}

MD received honoraria for lectures from Pulsion Medical Systems. NR received honoraria from Thermo Scientific Biomarkers for a lecture. $\mathrm{PH}$ received research support from Thermo Scientific Biomarkers and lecture and educational honoraria from Thermo Scientific Biomarkers, Radiometer and BioMérieux. The other authors report no conflicts of interest in this work.

\section{References}

1. Lopez AD, Shibuya K, Rao C, et al. Chronic obstructive pulmonary disease: current burden and future projections. Eur Respir J. 2006;27(2): $397-412$.

2. Patil SP, Krishnan JA, Lechtzin N, Diette GB. In-hospital mortality following acute exacerbations of chronic obstructive pulmonary disease. Arch Intern Med. 2003;163(10):1180-1186.

3. Connors AF, Dawson NV, Thomas C, et al. Outcomes following acute exacerbation of severe chronic obstructive lung disease. The SUPPORT investigators (Study to Understand Prognoses and Preferences for Outcomes and Risks of Treatments). Am J Respir Crit Care Med. 1996;154(4 pt 1):959-967.

4. Müllerova H, Maselli DJ, Locantore N, et al. Hospitalized exacerbations of chronic obstructive pulmonary disease: risk factors and outcomes in the ECLIPSE cohort. Chest. 2015;147(4):999-1007.

5. Gunen H, Hacievliyagil SS, Kosar F, et al. Factors affecting survival of hospitalised patients with COPD. Eur Respir J. 2005;26(2):234-241.

6. Nevins ML, Epstein SK. Predictors of outcome for patients with COPD requiring invasive mechanical ventilation. Chest. 2001;119(6): 1840-1849.

7. Seneff MG, Wagner DP, Wagner RP, Zimmerman JE, Knaus WA. Hospital and 1-year survival of patients admitted to intensive care units with acute exacerbation of chronic obstructive pulmonary disease. JAMA. 1995;274(23):1852-1857.

8. Roche N, Zureik M, Soussan D, Neukirch F, Perrotin D; Urgence BPCO (COPD Emergency) Scientific Committee. Predictors of outcomes in COPD exacerbation cases presenting to the emergency department. Eur Respir J. 2008;32(4):953-961.

9. Roche N, Chavaillon J-M, Maurer C, Zureik M, Piquet J. A clinical inhospital prognostic score for acute exacerbations of COPD. Respir Res. 2014;15:99.

10. Roche N, Rabbat A, Zureik M, Huchon G. Chronic obstructive pulmonary disease exacerbations in emergency departments: predictors of outcome. Curr Opin Pulm Med. 2010;16(2):112-117.

11. Stolz D, Christ-Crain M, Morgenthaler NG, et al. Plasma pro-adrenomedullin but not plasma pro-endothelin predicts survival in exacerbations of COPD. Chest. 2008;134(2):263-272.

12. Echevarria C, Steer J, Heslop-Marshall K, et al. Validation of the DECAF score to predict hospital mortality in acute exacerbations of COPD. Thorax. 2016;71(2):133-140.

13. Stolz D, Christ-Crain M, Morgenthaler NG, et al. Copeptin, C-reactive protein, and procalcitonin as prognostic biomarkers in acute exacerbation of COPD. Chest. 2007;131(4):1058-1067.

14. Vestbo J, Hurd SS, Agustí AG, et al. Global strategy for the diagnosis, management, and prevention of chronic obstructive pulmonary disease: GOLD executive summary. Am J Respir Crit Care Med. 2013; 187(4):347-365.
15. Sing T, Sander O, Beerenwinkel N, Lengauer T. ROCR: visualizing classifier performance in R. Bioinformatics. 2005;21(20):3940-3941.

16. Schuetz P, Hausfater P, Amin D, et al. Biomarkers from distinct biological pathways improve early risk stratification in medical emergency patients: the multinational, prospective, observational TRIAGE study. Crit Care. 2015;19:377.

17. Bello S, Lasierra AB, Mincholé E, et al. Prognostic power of proadrenomedullin in community-acquired pneumonia is independent of aetiology. Eur Respir J. 2012;39(5):1144-1155.

18. Brusse-Keizer M, Zuur-Telgen M, van der Palen J, et al. Adrenomedullin optimises mortality prediction in COPD patients. Respir Med. 2015; 109(6):734-742.

19. Stolz D, Breidthardt T, Christ-Crain M, et al. Use of B-type natriuretic peptide in the risk stratification of acute exacerbations of COPD. Chest. 2008;133(5):1088-1094.

20. Bernasconi M, Tamm M, Bingisser R, et al. Midregional proatrial natriuretic peptide predicts survival in exacerbations of COPD. Chest. 2011;140(1):91-99.

21. Morgenthaler NG, Struck J, Alonso C, Bergmann A. Measurement of midregional proadrenomedullin in plasma with an immunoluminometric assay. Clin Chem. 2005;51(10):1823-1829.

22. Struck J, Tao C, Morgenthaler NG, Bergmann A. Identification of an adrenomedullin precursor fragment in plasma of sepsis patients. Peptides. 2004;25(8):1369-1372.

23. Linscheid P, Seboek D, Zulewski H, Keller U, Müller B. Autocrine/ paracrine role of inflammation-mediated calcitonin gene-related peptide and adrenomedullin expression in human adipose tissue. Endocrinology. 2005; 146(6):2699-2708.

24. Meng D-Q, Li X-J, Song X-Y, Xin J-B, Yang W-B. Diagnostic and prognostic value of plasma adrenomedullin in COPD exacerbation. Respir Care. 2014;59(10):1542-1549.

25. Zuur-Telgen MC, Brusse-Keizer MGJ, Vandervalk PD, van der Palen J, Kerstjens HA, Hendrix MG. Stable state MR-proadrenomedullin level is a strong predictor for mortality in COPD patients. Chest. Epub 2013 Sep 26.

26. Bafadhel M, McKenna S, Terry S, et al. Acute exacerbations of chronic obstructive pulmonary disease: identification of biologic clusters and their biomarkers. Am J Respir Crit Care Med. 2011;184(6):662-671.

27. Vestbo J, Agusti A, Wouters EFM, et al. Should we view chronic obstructive pulmonary disease differently after ECLIPSE? A clinical perspective from the study team. Am J Respir Crit Care Med. 2014;189(9): $1022-1030$

28. Schuetz P, Marlowe RJ, Mueller B. The prognostic blood biomarker proadrenomedullin for outcome prediction in patients with chronic obstructive pulmonary disease (COPD): a qualitative clinical review. Clin Chem Lab Med. 2015;53(4):521-539.

29. Hausfater P, Claessens Y-E, Martinage A, et al. Prognostic value of PCT, copeptin, MR-proADM, MR-proANP and CT-proET-1 for severe acute dyspnea in the emergency department: the BIODINER study. Biomarkers. 1-7. Epub 2016 Jun 29.

30. Zhao Y, Jiang Y, Zhou L, Wu X. The value of assessment tests in patients with acute exacerbation of chronic obstructive pulmonary disease. Am J Med Sci. 2014;347(5):393-399.

31. Antonescu-Turcu AL, Tomic R. C-reactive protein and copeptin: prognostic predictors in chronic obstructive pulmonary disease exacerbations. Curr Opin Pulm Med. 2009;15(2):120-125. 


\section{Supplementary materials Patients and methods}

Blood sample for mid-regional pro-adrenomedullin (MR-proADM) and copeptin plasma level determination.

All blood samples were collected in plastic tubes containing ethylenediamine tetra-acetic acid, and plasma was stored at $-20^{\circ} \mathrm{C}$ in plastic freezer vials. MR-proADM was measured using an automated sandwich chemiluminescence immunoassay on the KRYPTOR system (BRAHMS AG, Hennigsdorf/Berlin, Germany). The lower detection limit of the assay was $0.05 \mathrm{nmol} / \mathrm{L}$, and the functional assay sensitivity was $0.25 \mathrm{nmol} / \mathrm{L}$. The technicians processing the blood samples were blinded from any patient data. Copeptin was measured using $50 \mu \mathrm{L}$ of ethylenediamine tetra-acetic acid plasma by a new sandwich immunoluminometric assay employing 2 polyclonal antibodies to amino acids 132-164 of preprovasopressin (C-terminal portion of pro-argininevasopressin by luminescence immunoassay; BRAHMS AG). The lower detection limit of the assay was $0.69 \mathrm{pmol} / \mathrm{L}$, and the functional assay sensitivity was $1.08 \mathrm{pmol} / \mathrm{L}$.

Table SI Characteristics and outcomes of patients meeting or not meeting the secondary (7-day) outcome

\begin{tabular}{|c|c|c|c|c|}
\hline \multirow[t]{2}{*}{ Characteristics } & \multirow{2}{*}{$\begin{array}{l}\text { All patients } \\
(n=276)\end{array}$} & \multicolumn{2}{|c|}{ Secondary outcome } & \multirow[t]{2}{*}{$P$-value } \\
\hline & & Yes $(n=34)$ & No $(n=242)$ & \\
\hline \multicolumn{5}{|l|}{ Increased/recent symptoms, n (\%) } \\
\hline Cough & $204(74)$ & $24(7 I)$ & $180(74)$ & 0.79 \\
\hline Expectoration abundance & 144 (52) & $20(59)$ & $124(5 \mid)$ & 0.53 \\
\hline Sputum purulence & $94(34)$ & $13(39)$ & $81(34)$ & 0.66 \\
\hline \multicolumn{5}{|l|}{ Signs of severity, $n(\%)$} \\
\hline 0 & $80(29)$ & $7(21)$ & $73(30)$ & 0.31 \\
\hline $1-2$ & $152(55)$ & $19(60)$ & $133(55)$ & \\
\hline$>3$ & $44(16)$ & $8(23)$ & $36(15)$ & \\
\hline Cyanosis & $48(17)$ & $7(2 I)$ & $4 I(17)$ & 0.78 \\
\hline Neurological impairment & $6(2)$ & $2(6)$ & $4(2)$ & 0.16 \\
\hline Lower limb edema & $53(19)$ & $7(2 I)$ & $46(19)$ & I \\
\hline Asterixis & $14(5)$ & $4(12)$ & $10(4)$ & 0.08 \\
\hline Use of accessory inspiratory muscles & $158(57)$ & $23(68)$ & $135(56)$ & 0.26 \\
\hline Expiratory use of abdominal muscles & $109(39)$ & $17(50)$ & $92(38)$ & 0.25 \\
\hline \multicolumn{5}{|l|}{ Physiological variables } \\
\hline SAP, $\mathrm{mmHg}$ & $142(123-160)$ & $145(|2|-\mid 77)$ & $142(123-160)$ & 0.41 \\
\hline $\mathrm{DAP}, \mathrm{mmHg}$ & $79(68-90)$ & $79(70-96)$ & $79.0(68-90)$ & 0.18 \\
\hline Respiratory rate, $\mathrm{min}^{-1}$ & $26(22-30)$ & $29(24-32)$ & $26(21-30)$ & 0.17 \\
\hline Heart rate, $\min ^{-1}$ & $95(84-108)$ & $91(78-106)$ & $96(84-109)$ & 0.28 \\
\hline $\mathrm{SpO}_{2}, \%$ & $93(90-96)$ & $94(91-97)$ & $93(90-96)$ & 0.25 \\
\hline \multicolumn{5}{|l|}{ Clinical risk score, $\mathrm{n}(\%)$} \\
\hline Low risk & $43(16)$ & $2(6)$ & $4 \mid(I 7)$ & 0.15 \\
\hline Intermediate risk & $113(4 I)$ & $13(38)$ & $100(4 I)$ & \\
\hline High risk & $120(43)$ & $19(56)$ & $101(42)$ & \\
\hline \multicolumn{5}{|l|}{ Blood gases } \\
\hline $\mathrm{pH}$ & $7.39(7.34-7.42)$ & $7.37(7.33-7.38)$ & $7.40(7.36-7.43)$ & 0.0006 \\
\hline $\mathrm{PaCO}_{2}, \mathrm{mmHg}$ & $46(39-56)$ & $55(43-64)$ & $46(39-55)$ & 0.011 \\
\hline $\mathrm{PaO}_{2}, \mathrm{mmHg}$ & $68(56.0-86)$ & $72.5(60-85)$ & $67(56-85)$ & 0.64 \\
\hline Lactate, $\mathrm{mmol} / \mathrm{L}$ & $1.2(1.0-1.8)$ & I.3 (0.9-I.7) & $1.2(1.0-1.8)$ & 0.78 \\
\hline \multicolumn{5}{|l|}{ Treatments in ER, $\mathrm{n}(\%)$} \\
\hline Short-term $\beta 2$-agonists & $244(88.4)$ & 31 (9I.2) & $213(88.0)$ & 0.80 \\
\hline Anticholinergic agents & $227(82.2)$ & $27(79.4)$ & $200(82.6)$ & 0.82 \\
\hline Oral corticosteroids & $27(9.8)$ & $3(8.8)$ & $24(9.9)$ & I \\
\hline Oxygen therapy & $124(44.9)$ & $15(44.1)$ & $109(45.0)$ & I \\
\hline Noninvasive ventilation & $45(16.3)$ & $8(23.5)$ & $37(15.3)$ & 0.33 \\
\hline \multicolumn{5}{|l|}{ Biomarkers } \\
\hline MR-proADM, nmol/L & $0.87(0.67-1.15)$ & $1.18(0.8 \mathrm{I}-1.86)$ & $0.84(0.67-I . I I)$ & 0.003 \\
\hline Copeptin, pmol/L & $13.06(5.93-33.52)$ & $30.12(7.6 I-78.01)$ & I I.78 (5.84-30.82) & 0.004 \\
\hline
\end{tabular}

Abbreviations: ER, emergency room; MR-proADM, mid-regional pro-adrenomedullin; SAP, systolic arterial pressure; DAP, diastolic arterial pressure. 
Table S2 Correlation between MR-proADM and clinical and biological variables (Spearman correlation)

\begin{tabular}{|c|c|c|}
\hline Variables & Spearman coefficient & P-value \\
\hline \multicolumn{3}{|l|}{ Clinical } \\
\hline Systolic arterial pressure, $\mathrm{mmHg}$ & $<0.0001$ & 0.99 \\
\hline Diastolic arterial pressure, $\mathrm{mmHg}$ & -0.09 & 0.07 \\
\hline Heart rate, $\mathrm{min}^{-1}$ & -0.02 & 0.73 \\
\hline Respiratory rate, $\mathrm{min}^{-1}$ & 0.11 & 0.05 \\
\hline Temperature, ${ }^{\circ} \mathrm{C}$ & 0.25 & $<0.000$ I \\
\hline $\mathrm{SpO}_{2}, \%$ & -0.1 & 0.05 \\
\hline \multicolumn{3}{|l|}{ Arterial blood gases } \\
\hline $\mathrm{pH}$ & -0.08 & 0.13 \\
\hline $\mathrm{PaCO}_{2}, \mathrm{mmHg}$ & 0.02 & 0.72 \\
\hline $\mathrm{PaO}_{2}, \mathrm{mmHg}$ & -0.07 & 0.17 \\
\hline Lactate, $\mathrm{mmol} / \mathrm{L}$ & 0.2 & $<0.05$ \\
\hline
\end{tabular}

Abbreviation: MR-proADM, mid-regional pro-adrenomedullin.
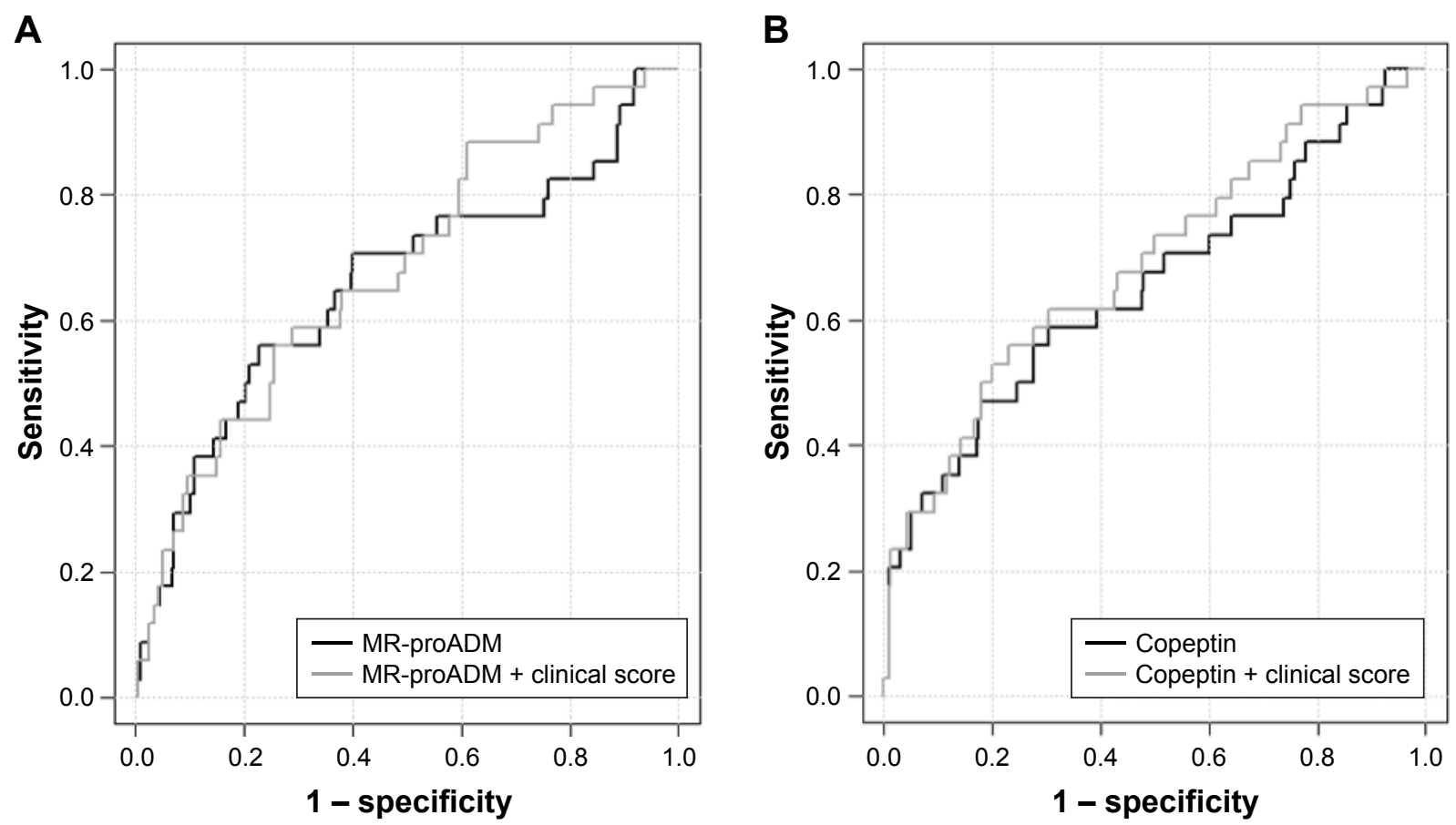

Figure SI ROC curves showing the performance of the plasma level of MR-proADM or MR-proADM (A) associated with clinical risk score and of copeptin or copeptin (B) associated with clinical score to predict the occurrence of the secondary end point.

Abbreviations: MR-proADM, mid-regional pro-adrenomedullin; ROC, receiver operating characteristic.

\section{Publish your work in this journal}

The International Journal of COPD is an international, peer-reviewed journal of therapeutics and pharmacology focusing on concise rapid reporting of clinical studies and reviews in COPD. Special focus is given to the pathophysiological processes underlying the disease, intervention programs, patient focused education, and self management protocols.
This journal is indexed on PubMed Central, MedLine and CAS. The manuscript management system is completely online and includes a very quick and fair peer-review system, which is all easy to use. Visit http://www.dovepress.com/testimonials.php to read real quotes from published authors. 